\section{Japan gears up to debate brake on human cloning}

[Tокуо] Japan's Council for Science and Technology, the principal science policy-making body which is chaired by the prime minister, is setting up a committee to discuss a possible legal ban on human cloning.

The move was announced last week and coincided with the signing by 19 European countries of a convention in which they agreed to introduce legislation to ban human cloning for reproductive purposes (see Nature 391, 219; 1998).

The Japanese committee will be made up of experts in ethics, medicine and the law, and plans to hold its first meeting in February. It aims to reach an agreement on its recommendations by May, in time for the G7 meeting of the leaders of the advanced industrialized countries to be held in Birmingham, in the United Kingdom, at which issues raised by human cloning are scheduled to be discussed.

Keiichi Tanigaki, director-general of Japan's Science and Technology Agency (STA), said at a meeting of the council last week that the cloning of humans is "a fundamental issue in bioethics", and that an "open and nationwide debate" is needed in Japan before a decision is made on how it should be controlled.

But critics point out that the committee's meetings will be closed to the public, in contrast to similar meetings at ministries such as the Ministry of Health and Welfare.

The issue of human cloning "requires careful and determined consideration" says Norio Fujiki, an emeritus professor at Fukui Medical School and one of Japan's leading bioethicists. "The first step requires the involvement of people from different fields, so that extensive discussions can take place."

Since last year's birth in Scotland of Dolly, the cloned lamb, the council has repeatedly asked Japanese researchers in the public and private sectors to hold back from carrying out research into human cloning. The STA and the Ministry of Education, Science, Sports and Culture (Monbusho) have responded by announcing plans to limit their funding and research in this area until proper guidelines have been laid down.

A protocol protecting human embryos already exists in Japan; donating eggs is illegal under ethical rules laid down by the Japanese Society of Obstetrics and Gynaecology. But there are loopholes. It was recently revealed that a Japanese couple had agreed to donate fertilized eggs to an American couple, and that there have been more than 100 cases of such 'adoption' from Japan. Although this practice is prohibited in Japan, it is legal in the United States.

Asako Saegusa

\title{
UK's food standards agency will report to health minister
}

[LONDON] The UK government revealed its plans for an independent food standards agency last week, responding to pressures that have built up steadily since the recent crisis over bovine spongiform encephalopathy (BSE) and other food safety scares

The agency will be created by a merger of the food safety, research and nutrition divisions of the Ministry of Agriculture, Fisheries and Food (MAFF) and the Department of Health, and will have the power to enforce food safety "from plough to plate".

Although about 80 per cent of its staff of several hundred will come from MAFF, it has been decided - after what is said to have been an intense internal battle in Whitehall - that the agency will report to the health minister. It is expected to be set up by the middle of next year, after further public consultations and parliamentary debate.

In a white paper (policy document) setting out its proposals, the government says the agency will be headed by a chief executive and 12 commissioners, most of whom will be drawn from public and consumer interests. Its $\mathfrak{£} 100$-million (US\$150 million) annual budget will be met from a levy on the food industry, and the agency will also take charge of the agriculture ministry's annual $£ 25$-million food safety research budget.

The announcement has been welcomed by consumer groups, such as the Consumers Association, and by many food scientists. The proposals are based almost entirely on a report written by Philip James, director of the Rowett Research Institute in Aberdeen, at the invitation of the Prime Minister, Tony Blair, in March last year, when he was still in opposition. Another of James's proposals — that there should be increased public representation on government expert advisory committees — is already being implemented.

At the core of the white paper is the decision to take responsibility for food safety away from MAFF. The potential for a conflict of interest in a single ministry representing the interests of both producers and consumers of beef had been flagged by observers for some years.

At the white paper's launch in London last week, Jack Cunningham, the agriculture minister, acknowledged that "people had long argued that this [arrangement] was flawed and not in the public interest".

The issue came to a head during the late 1980 s and early 1990s with MAFF's apparent reluctance to take stronger action to protect consumers from eating meat infected with BSE, because of pressure from farmers who feared that further protective measures would lead to industry losses.

Measures were belatedly taken when scientists announced the possibility that eating BSE-infected meat may have caused the neurodegenerative disorder CreutzfeldtJakob disease (see Nature 380, 273; 1996).

The decision to place food safety research in the hands of the agency reflects a view that the influence of the food industry lobby may have obstructed open and transparent publication of the agriculture ministry's research. Indeed, some critics, such as Erik Millstone, a food policy researcher at the Science Policy Research Unit at the University of Sussex, fear that MAFF may still find it difficult to relinquish control over both food safety and

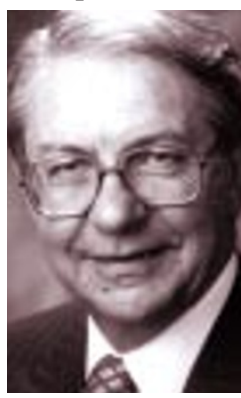

James: proposals are based on his report. research to the food standards agency.

Between now and the launch of the agency, all new research proposals will be looked at by the independent expert committee that advises the government on food science. But its main food and agriculture research laboratory - the Central Science Laboratory - is to remain under MAFF's control, suggesting that the ministry is not about to let go.

Millstone says that he is also worried about a passage in the white paper that says the agency "will be required to consult agriculture ministers" when considering new measures to be added to the Food Safety Act.

While the agency retains powers to override agriculture ministers, Millstone believes that this will be difficult in practice, as the agency's commissioners may well be "too intimidated" to ignore ministerial advice. He also questions the constitutional basis for "unelected officials overriding elected members of the government".

But the view that the continued involvement of MAFF represents bad news for research is not shared by all researchers. Bronek Wedzicha, head of the department of food science at the University of Leeds, for example, says he has never been prevented from publishing research funded by the agriculture ministry.

Wedzicha says that scientists need to understand that the scientific civil service operates in a different way from mainstream science. "If you have a finding, don't act recklessly, insisting on the right to publish anywhere you like," he says. "Reason with them, and they'll come round to your point of view."

EhsanMasood 